\title{
The cross-sectional impact of income inequality on life quality indicators
}

\author{
Xiaotong $\mathrm{Xi}^{*}$ \\ Shanghai United International School, Shanghai, China
}

\author{
Keywords \\ Cross-sectional \\ Impact \\ Income inequality \\ Life quality indicators \\ Received: 11 March 2020 \\ Accepted: 21 May 2020 \\ Published: 12 August 2020
}

\begin{abstract}
This paper studies the consequences of income inequality on life quality in a subset of selected countries. Specifically, I examine the impact of ( $\log$ GDP per capita and the Gini coefficient of income inequality on a set of life quality indicators. This paper relies on the data from the World Bank, which provides statistics for almost all the information that is required for inequality and other measures of living standards for different countries around the world. The data was collected from 2010, as it gives the best trade-off between being the most recent and not having too much missing data. First, both life expectancy and infant mortality are improved when there is less inequality, and the country is wealthier. Second, the effect on crime statistics is more mixed. While theft increases with GDP per capita, the inequality does not seem to play a role; conversely, homicide increases in inequality but remains unaffected by GDP. Results indicate that the influence of Gini co-efficient and log GDP per capita may vary among different categories of crime. The R-squared shows that the two factors could only explain $35.7 \%$ of changes in the homicide rate. Plausible explanations for these empirical observations are offered throughout the paper. The unavailability of data could also be a factor that influences the final results, particularly for Gini co-efficient; out of the 216 existing countries, I only gather the full set of data for 84 of them. Therefore, access to more data could further improve my results.
\end{abstract}

(C) 2020 The Author(s). Published by TAF Publishing.

\section{INTRODUCTION}

Inequality within and amongst countries has been a problem that could be considered as invincible since the class and hierarchy has become a phenomenon in the human history. After the UN has included equality in its sustainable development goals (Ayuningrat, Noermijati., \& Hadiwidjojo, 2016; United Nations, 2020), equality has drawn scholars' attention from different areas of study. There are numerous channels through which inequality may result in varying levels of living standards for the residents of a country or an area. A country may have an extremely high GDP or GDP per capita, but in real life $70 \%$ of the income and output may be concentrated in the top 5\% of the population (Liu \& Dong, 2016; Qekwana, Oguttu, Venter, \& Odoi, 2016). At the same time, another country may have a lower GDP but one which is equally distributed. Such a country may have a better living standard because all citizens are able to enjoy similar level of goods and services provision. This is why the governments are working towards the goal of reducing income inequality.

It has long been a well-established fact that the level of GDP per capita has an impact on measures of living standards such as health statistics and crime rates. For the former, with higher GDP per capita, people suffering from diseases would have more money for medical treatments, might be able to afford regular checks annually, and would have access to healthcare service of superior quality. For the latter, higher GDP per capita could reduce the amount of crime triggered by economic reasons such as stealing or robbery. However, these measures of living standards may also be affected by the degree of equality of a country. When countries are more equal, they usually have advanced medical facilities available to everyone as well as high living standards which also reduce the crime rate of that country. This

\footnotetext{
* corresponding author: Xiaotong Xi

†email: 1192627348@qq.com
} 
makes equality significant when it comes to an increase in living standard. A measure of inequality used in this paper is the Gini coefficient, which attempts to capture the statistical dispersion of incomes amongst the residents of the country. The lower the Gini coefficient is, the lower the inequality is. Among the factors that could indicative of living standards, which I examine in this paper, are crime rates, and life expectancy as well as infant mortality rates. Life expectancy and infant mortality rates could be a reflection of the general level of health in the population. Comparing the overall trends in the data may allow us to establish and draw conclusions about the correlations between equality and the indicators of living standards.

This paper is aiming to prove the hypothesis that inequality is affecting various measures of living standards. It is organized as follows: first, I review literature works that is related to this topic. Next I describe the data that I processed. Then I present and analyze the measures of living standards: life expectancy, infant mortality, theft rate and homicide rate. I also compare whether the Gini coefficient and/or the GDP per capita has a larger impact on them. Finally, I conclude and evaluate the results of my research.

\section{LITERATURE REVIEW}

de Meijer, O'Donnell, Koopmanschap, and Van Doorslaer (2013) find that there is always a positive relationship between income and health which makes them interested in the influence of income distribution on health. They note that there are factors like heritable diseases which affect the results. When comparing different countries, the results differ because there are other factors affecting health, like climate and infectious disease which infect numerous of people at once. Although at high-income countries, the relationship between health of adults and wealth inequality is ambiguous.Their conclusion is the living conditions of the poor, and not their relative deprivation, that takes the toll on health.

As already mentioned, the correlation between income and health statistics is positive. Part of the explanation is that down the income hierarchy, the chance of getting illnesses increases, since people have poorer living standards and may get sickness from sources such as poor sanitation and imbalanced diets. The data comparing a set of countries showed that the infant mortality is considerably below the average and life expectancy is considerably above the average for the $5 \%$ of top income earners. However, these results should be interpreted with caution as statistics comparing different countries may be inaccurate, unreliable, or outdated. When comparing statistics within the country, the results are supporting conclusions akin to those in the cross-country investigations (Kawachi \& Berkman, 2003; Putri, 2015; Wartika, Surendro, Satramihardja, \& Supriana, 2015).

Stack (1984) sets up a test for the link between the income inequality and property crime. He looks at a set of 62 countries. The control variable that he uses is economic development because the more economically developed a country is, the less likely crime is going to happen. The conclusion he finds is that inequality and property crime are not clearly correlated. However, inequality has a negative relationship with alcoholism, suicide and various aspects of crime. He also finds that inequality leads to an increased level of crime only under the condition of political tension (Hairudinor, Hidayati, Muspiron., Tampubolon, \& Humaidi., 2017; Rafiah \& Ariyanti, 2017; Stack, 1984).

Choe (2008) mentions that there exist not only studies that find that inequality and crimes such as robbery and theft have a strong correlation but also papers that suggest the opposite. His research is based on data from the United States. His study demonstrates that the income inequality as measured by the Gini coefficient has a clear correlation with burglary and theft, but fails to find a relationship between income inequality and other crime statistics, in particular murder (Choe, 2008).

Kelly (2000) investigated the relationship between inequality and crime. An unprecedented approach was using the method of elasticity, to determine whether wealth inequality impacts violent crime, and the result was 0.5 , indicating the robust relationship between them. However, the effect on property crime can be negligible. Based on theoretical models, they concluded that violent crime can be demonstrated clearly by strain and social disorganization theories (Kelly, 2000).

The relationship between health and inequality is significant to consider, aspects of health should not only include physical health, but can also consider mental wellbeing, drug use, obesity and many other factors. The result again shows a positive correlation between the two variables, and it indicated the social sensitivity and status of competition in a country and reflects social problems at the same time (Berkman \& Glass, 2000).

The entropy index and the Atkinson index are alternatives to Gini coefficient, also measuring the wealth gap between different groups in a population. Multiple methods will give researchers a clearer and more precise result (De Maio, 2007). 


\section{RESEARCH METHODOLOGY}

This paper relies on the data from the World Bank, which provides statistics for almost all the information that is required for inequality and other measures of living standards for different countries around the world. I compile data for 216 countries; however some data was missing, and some was out of date. The variables included are GDP per capita (in US dollars per person), Gini coefficient (in\%), life expectancy (in years), infant mortality (per 1,000 live births). I have also collected data on homicide and theft rates (in number of homicides per 10,000 people) from United $\mathrm{Na}-$ tions Office on Drugs and Crime. The data was collected from 2010, as it gives the best trade-off between being the most recent and not having too many missing data.

\section{RESULTS AND DISCUSSION}

It can be observed that while the Gini coefficient can theoretically take values from 0 to 100 , most of the countries are concentrated in the range of 20-40. The distribution displays right skewness, which means that while there are countries that are considerably more unequal than the median country, though there are not many of them. I am now going to examine the impact of the Gini coefficient on the various indicators of living standards mentioned above.

\section{Life Expectancy}

The distribution of life expectancy shows that most countries are located around the age of approximately 74-75 years old, but there is a long tail of countries where the life expectancy is significantly lower. I begin by analyzing the simple relationship between the Gini coefficient and the life expectancy. Compiling the data for Gini and life expectancy into a scatter diagram shows a trend that countries with a lower Gini coefficient (more equal) tend to have a higher life expectancy, as can be seen in Figure 1. If we were to draw a best fit line, it would be downward sloping. The regression of life expectancy on Gini coefficient demonstrates that when Gini coefficient increases by 1, the life expectancy would decrease by approximately 0.41 years. This relationship was found to be statistically significant (see Table 1).

TABLE 1. Regression of life expectancy on Gini coefficient

\begin{tabular}{lllll}
\hline \hline Source & SS & $\boldsymbol{d} \boldsymbol{f}$ & MS Number of Obs & $\mathbf{8 3}$ \\
\hline \multirow{2}{*}{ Model } & $F(2,80)=$ & 51.26 & & \\
Residual & 2303.11117 & 2 & Prob $>F=$ & 0.0000 \\
& 1797.20971 & 80 & $R$-squared $=$ & 0.5617 \\
Total & Adj $R$-squared $=$ & 0.5507 & & \\
LifeExpect y & 4100.32088 & 82 & Root MSE $=$ & 4.7397 \\
Gini & Coef. & Std. Err. & $t p>t[95 \%$ Conf. & Interval] \\
GdpPerCapita & -.1716824 & .0694812 & $-2.470 .016-.3099543$ & -.0334105 \\
_cons & .0002755 & .0000357 & 7.710 .000 .0002045 & .0003466 \\
\hline \hline
\end{tabular}

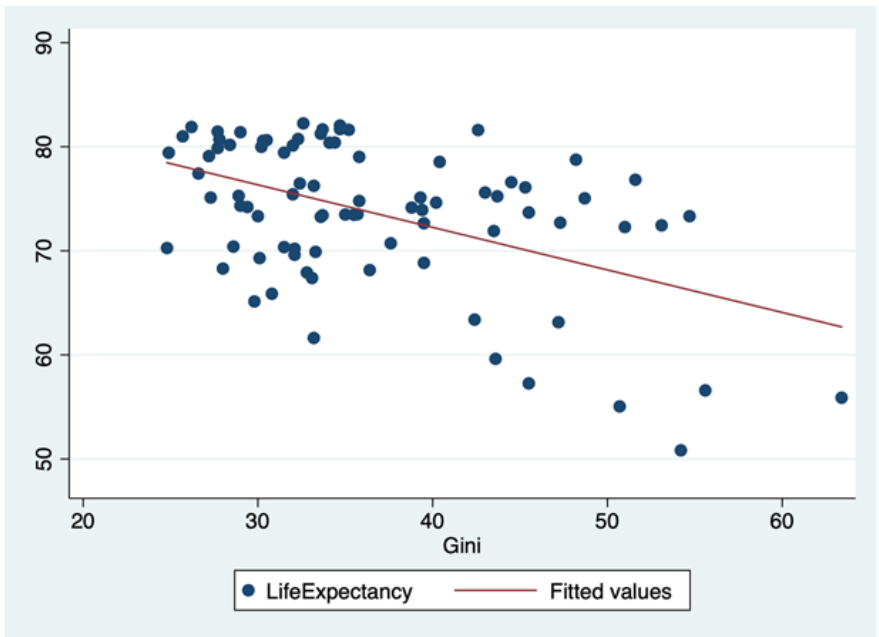

FIGURE 1. Scatterplot of life expectancy and Gini coefficient 
The main weakness of the above regression is that it fails to account for the direct impact of the GDP per capita, which is a major determinant of the health outcomes (the richer the country is, the better the quality of diet and healthcare, and so the longer people live, other things equal). Hence, I will now include GDP per capita in my regression. The relationship between GDP per capita and life expectancy could also be seen in Figure 2.

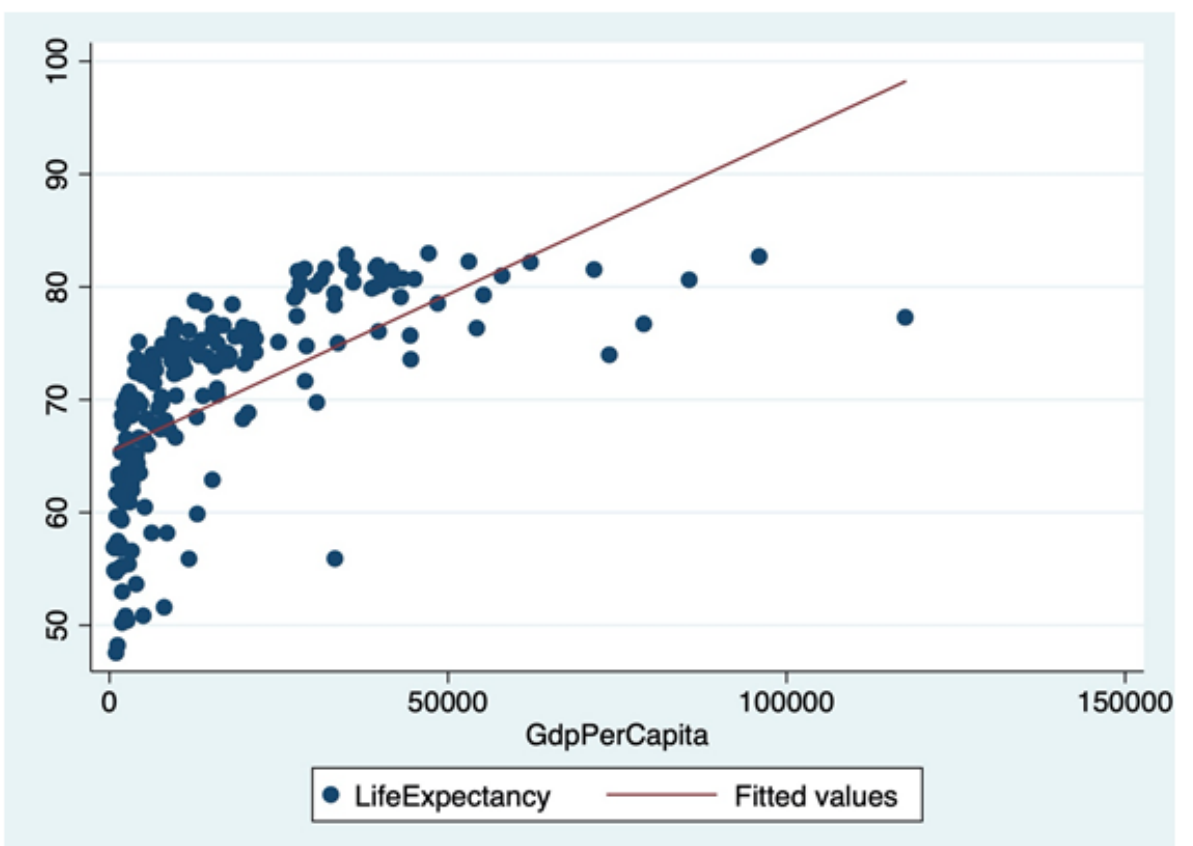

FIGURE 2. Scatterplot of life expectancy and GDP per capita (in US dollars)

However, we can observe that the relationship between the variables is not linear, but rather logarithmic. This is presumably because an increase in GDP per capita has a larger positive impact on life expectancy in a poor country than in rich country. The reason is presumably that rich countries already have well-developed medical facilities and treatments available, so significant improvements are difficult.
At the same time, poor countries would be able to afford medical treatments that they were not able to enjoy before. In order to obtain a linear relationship, I transform GDP per capita to log GDP per capita. As a result, the life expectancy can be seen to increase approximately linearly with log GDP per capita (see Figure 3).

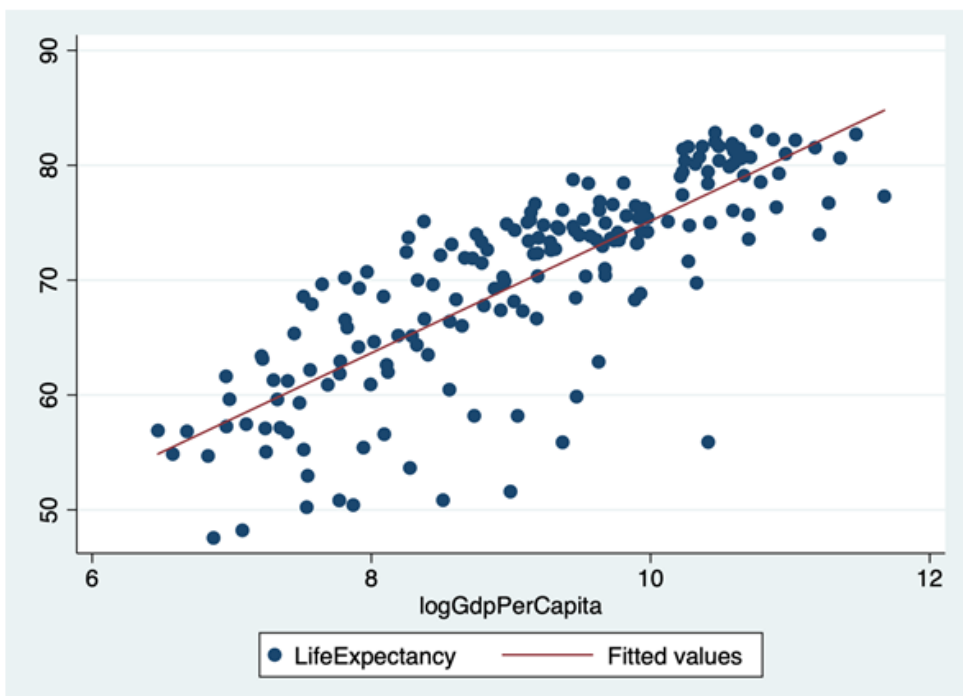

FIGURE 3. Scatterplot of life expectancy and log GDP per capita 
The regression of life expectancy on log GDP per capita shows that when log GDP per capita increases by 1 , the life expectancy would increase by about 5.1. This means that if GDP per capita of a county increases from $\$ 1,000$ to $\$ 10,000$, such a country would enjoy a 5.1-year boost to its life expectancy. However, a country whose GDP per capita was originally $\$ 10,000$ would need to raise it to $\$ 100,000$ to achieve the same boost in life expectancy.

The above results lead us to examine our main object of interest: the effect that the Gini coefficient and log GDP per capita have on life expectancy jointly. The regression from
Table 2 is statistically significant and the R-squared suggests that these two independent variables explain $72.7 \%$ of variability in life expectancy. Both variables are individually significant, with higher Gini and lower (log) GDP per capita leading to lower life expectancy. However, the impact of the Gini coefficient is now considerably smaller than in the standalone regression, which results from the fact that it is the poorer countries that tend to be more unequal. In our result, if the Gini coefficient increased by one, the life expectancy would be reduced by 0.14 years.

TABLE 2. Regression of life expectancy on Gini coefficient and log GDP per capita

\begin{tabular}{lllll}
\hline \hline Source & SS & $\boldsymbol{d}$ f & MS Number of obs & $\mathbf{8 3}$ \\
\hline \multirow{3}{*}{ Model } & $F(2,80)=$ & 106.94 & & \\
Residual & 2984.15446 & 21492.07723 & Prob $>F=$ & 0.0000 \\
& 1116.16643 & 8013.9520803 & R-squared $=$ & 0.7278 \\
Total & Adj $R$-squared $=$ & 0.7210 & & \\
LifeExpectancy & 4100.32088 & 8250.0039132 & Root MSE $=$ & 3.7352 \\
Gini & Coef. & Std. Err. $t$ & $p>t$ [95\% Conf. & Interval] \\
LogGdpPerCapita & 5.079162 & $.0540657-2.53$ & $0.013-.2443797$ & -.0291912 \\
cons & 30.64065 .1596085 .94 & .422352412 .03 & 0.0004 .238654 & 5.91967 \\
\hline \hline
\end{tabular}

\section{Infant Mortality}

Infant mortality is another indication of a country's overall level of health. It measures the number of deaths per 1000 infants under the age of one. This can be considered to be indicative of the quality of a country's medical facilities when dealing with infants.

Figure 4 shows a scatter plot that plots the infant mortality rate against the Gini coefficient. The two variables seem to have a positive relationship shown by the line of best fit, so it seems to be the case that the lower the infant mortality rate, the lower the Gini coefficient. However, the trend indicated by the line of best fit is not perfect. Table 3 shows the regression of infant mortality rate and Gini coefficient indicates that when the Gini coefficient increases by 1 , the infant mortality rate would increase by approximately 1 extra death per 1,000 infants.

However, such an analysis suffers from problems similar to those discussed in the previous section. Infant mortality is also supported not only by the level of equality in a country, but also directly by the GDP per capita. A scatter plot for infant mortality and GDP per capita is a downward sloping line, which means, the higher the GDP per capita, the lower the infant mortality rate. This is shown in Figures 5 and 6, which again supports the fact that inequality is not the only factor that influences country's health outcomes. Following the same argument as in the previous section, log GDP per capita instead of plain GDP per capita could be used to better fit the data.

TABLE 3. Regression of infant mortality rate on Gini coefficient

\begin{tabular}{|c|c|c|c|c|}
\hline Source & SS & $d f$ & MS Number of obs & 83 \\
\hline & $F(1,81)=$ & 24.12 & & \\
\hline Model & 5793.39849 & 1 & 5793.39849 Prob $>F=$ & 0.0000 \\
\hline \multirow[t]{2}{*}{ Residual } & 19455.6733 & 81 & 240.193498 R-squared = & 0.2294 \\
\hline & Adj $R$-squared = & 0.2199 & & \\
\hline Total & 25249.0718 & 82 & 307.91551 Root MSE = & 15.498 \\
\hline InfantMort y & Coef. & Std. Err. $t$ & $p>t[95 \%$ Conf. & Interval] \\
\hline Gini & 1.001132 & .2038474 & 4.910 .000 .5955393 & 1.406724 \\
\hline _cons & -20.20049 & 7.659241 & $-2.640 .010-35.43998$ & -4.961007 \\
\hline
\end{tabular}




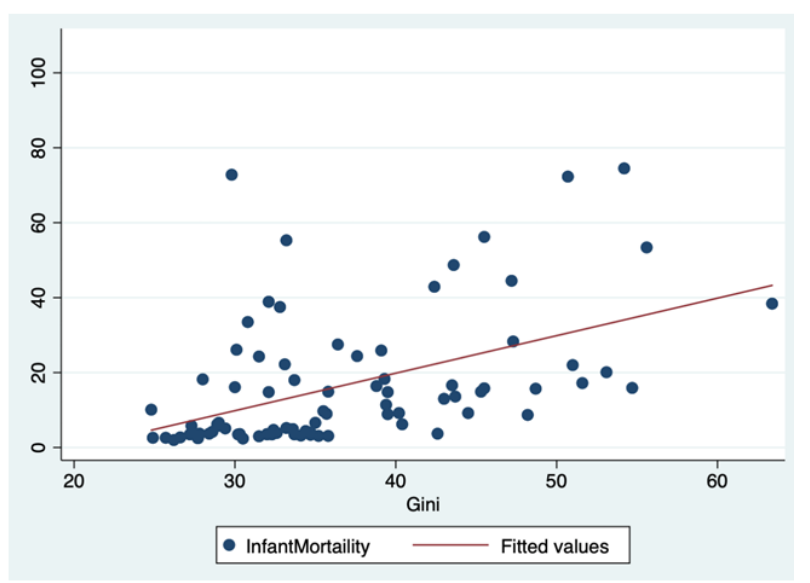

FIGURE 4. Scatterplot of infant mortality rate and Gini coefficient

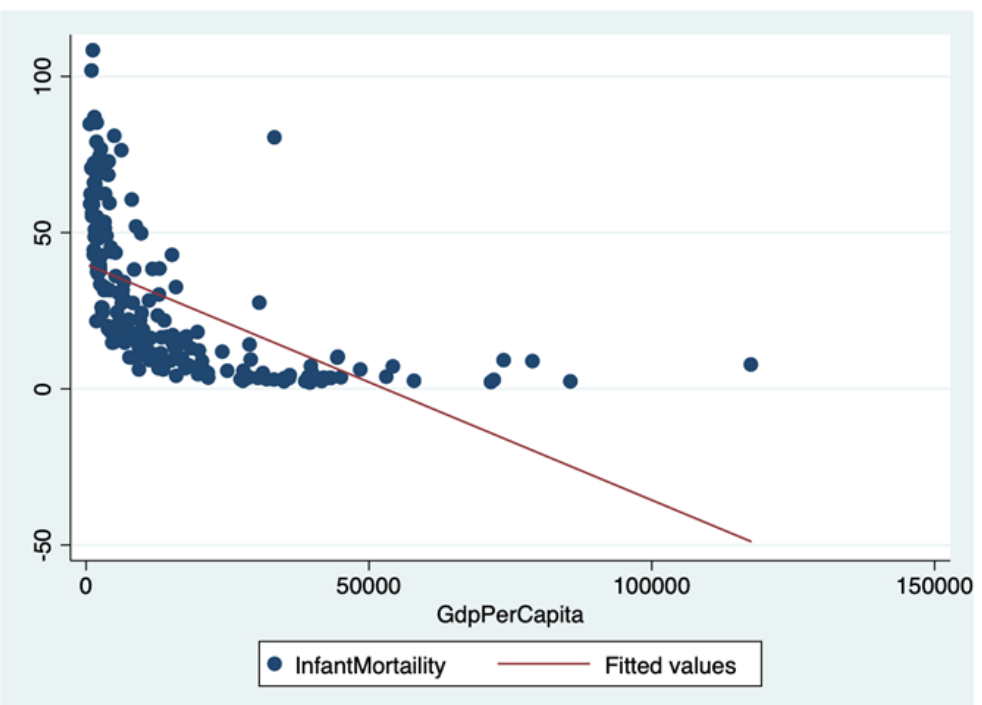

FIGURE 5. Scatterplot of infant mortality rate and GDP per capita (in US dollars)

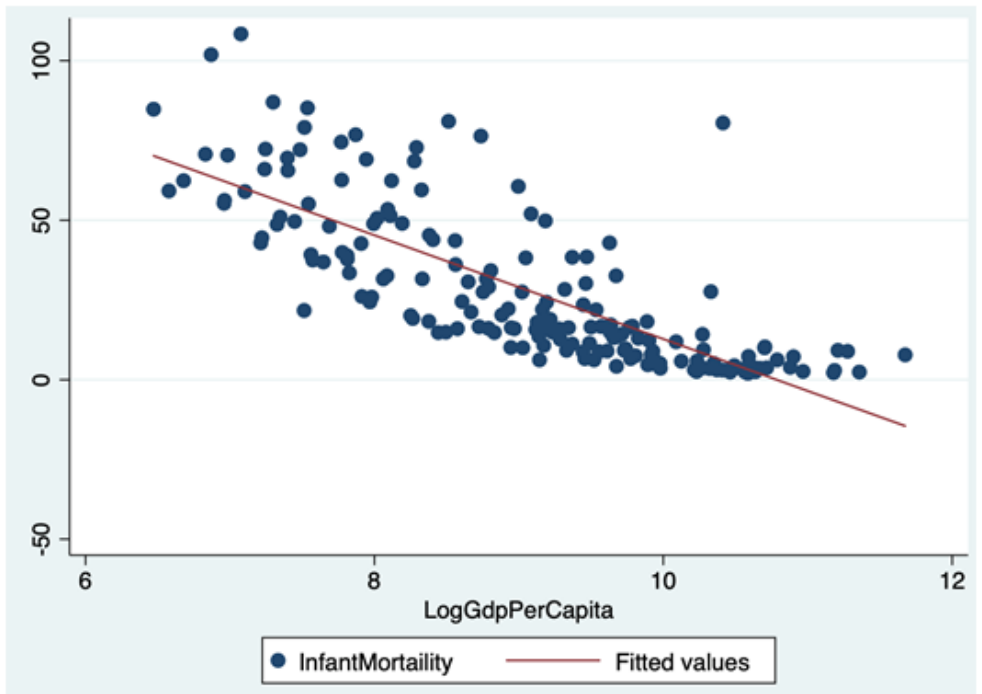

FIGURE 6. Scatterplot of infant mortality rate and log GDP per capita 
TABLE 4. Regression of infant mortality rate on Gini coefficient and log GDP per capita

\begin{tabular}{lllll}
\hline \hline Source & SS & $\boldsymbol{d} \boldsymbol{f}$ & MS Number of obs & $\mathbf{8 3}$ \\
\hline \multirow{2}{*}{ Model } & $F(2,80)=$ & 107.23 & & \\
Residual & 18389.2574 & 29194.62869 & Prob $>F=$ & 0.0000 \\
& 6859.81442 & 8085.7476803 & $R$-squared $=$ & 0.7283 \\
Total & Adj $R$-squared $=$ & 0.7215 & & \\
InfantMortail y & 25249.0718 & 82307.91551 & Root MSE $=$ & 9.26 \\
Gini & Coef. & Std. Err. $t$ & $p>t[95 \%$ Conf. & Interval] \\
LogGdpPerCapita & .3153256 & .13429922 .35 & 0.021 .0480617 & .5825895 \\
_cons & -12.58422 & $1.038302-12.120 .000$ & -14.65051 & -10.51794 \\
\hline \hline
\end{tabular}

The $R$-squared of the regression of the infant mortality rate on the Gini coefficient and the log GDP per capita is $72.8 \%$. This means both variables are significant to consider. The regression shows that when the Gini coefficient increases by 1 , the infant mortality rate is going to increase by 0.32 deaths per 1,000 children, while a tenfold increase in GDP per capita would lead to a decrease in the infant mortality rate of 12.58 deaths per 1,000 children.

\section{Crime: Theft}

Theft refers to the crimes of stealing and robbery. The scatter plot between theft rate and the Gini coefficient in Figure 7 shows significant dispersion in the data. However, the line of best fit seems to be downward sloping. This would mean that the more equal a country is, the more likely crimes like theft are going to happen. Higher equality in a country would usually enjoy higher living standards, which could lead to more frequent theft since there are more potential targets for thieves.

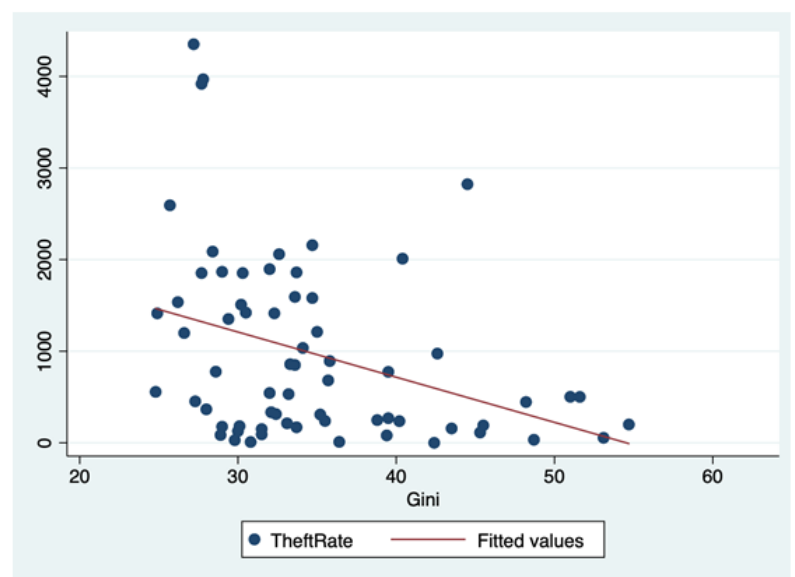

FIGURE 7. Scatterplot of theft rate and Gini coefficient

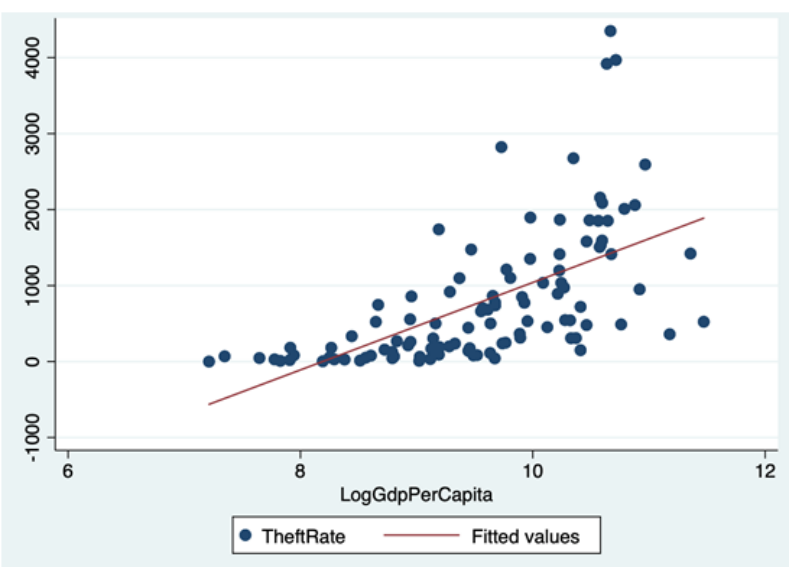

FIGURE 8. Scatterplot of theft rate and log GDP per capita 
As in previous experiments, the effect of GDP per capita on crime rates is not linear, so I again use the logarithmic transformation. Figure 8 demonstrates the relationship between theft rate and log GDP per capita for almost all countries in the world. The upward-sloping line of best fit shows that the higher the GDP per capita (higher income and living standards) leads to more possibilities for theft and consequently more theft. This is acceptable due to the fact that when people are earning more, there are usually more targets for thieves, whereas if the vast majority in one country are all living on small incomes, this demotivates thieves as well. However, such an interpretation might be somewhat misleading as in relatively poor countries most theft may not even be reported to the government since people are so used to it and police is inefficient. This largely affects a country's theft rate and may therefore change the result.

TABLE 5. Regression of theft rate on Gini coefficient and log GDP per capita

\begin{tabular}{lllll}
\hline \hline Source & SS & $\boldsymbol{d} \boldsymbol{f}$ & MS Number of obs & $\mathbf{8 3}$ \\
\hline \multirow{2}{*}{ Model } & $F(2,63)=$ & 26.81 & & \\
Residual & 30332168.5 & 215166084.3 & Prob $>F=$ & 0.0000 \\
& 35640020.1 & 63565714.605 & $R$-squared $=$ & 0.4598 \\
Total & Adj $R$-squared $=$ & 0.4426 & & \\
TheftRate & 65972188.6 & 651014956.75 & Root MSE $=$ & 752.14 \\
Gini & Coef. & Std. Err. $t$ & $p>t[95 \%$ Conf. & Interval] \\
LogGdpPerCapita & 733.6874 & $13.60789-1.47$ & $0.147-47.16249$ & 7.223924 \\
_cons & -19.96928 & 117.94916 .22 & 0.000497 .985 & 969.3898 \\
\hline \hline
\end{tabular}

The regression of theft rate on the Gini coefficient and the $\log$ GDP per capita is then conducted jointly in Table 6 . The R-squared indicates that Gini coefficient and log GDP per capita only explain $45.9 \%$ of the variability in the theft rate. The lower the (log) GDP per capita is prompting a society with less theft. However, the impact of inequality is not statistically significant. Consequently, unlike the health outcomes, theft seems to display quite behavior: first, it increases and not falls with higher incomes, and second the inequality does not seem to play any significant role.

\section{Crime: Homicide}

Homicides consists of all types of killings including suicide and murder. Their number (relative to the total population) can reflect the living standards of a country. The homicide rate and Gini coefficient for different countries across the world is demonstrated in Figure 9. There is an obvious positive correlation between the two variables: the increase in the Gini seems to result in an increase in the homicide rate. This means that as countries are getting more unequal, there is a higher chance of murder and suicide.

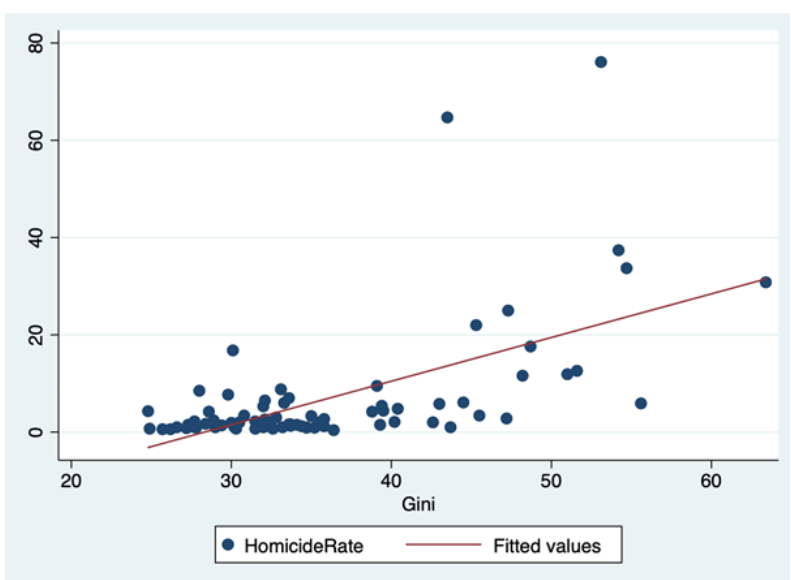

FIGURE 9. Scatterplot of homicide rate and Gini coefficient 


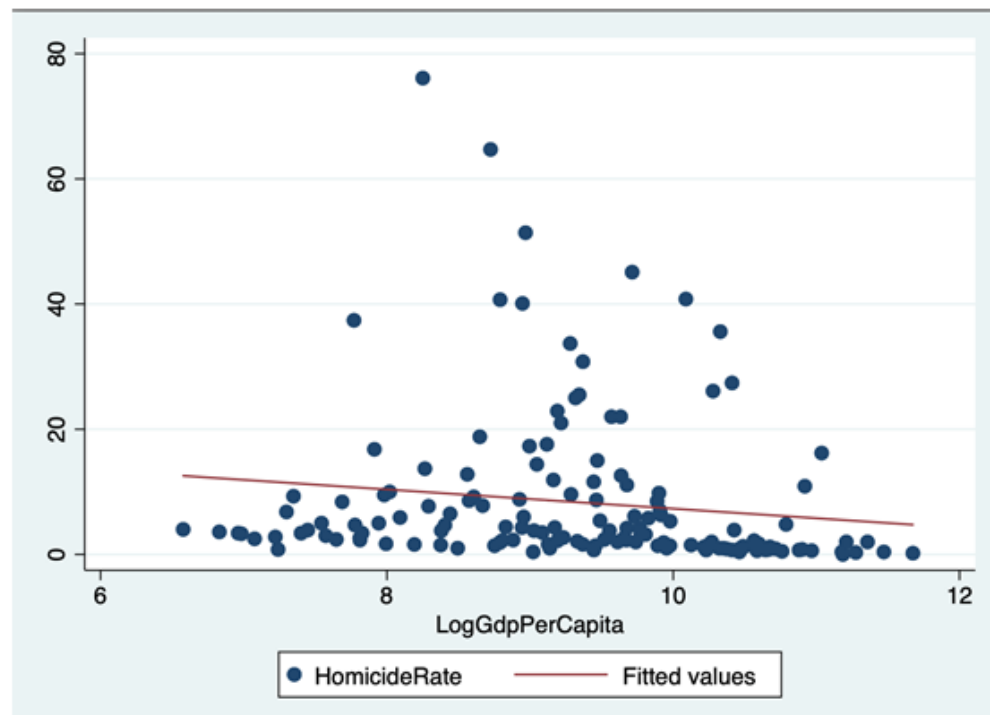

FIGURE 10. Scatterplot of homicide rate and log GDP per capita

Figure 10 above examines the relationship between the homicide rate and the log GDP per capita. Most points are crowded near the X-axis, which means that the homicide rate is generally quite low and does not appear to change with the GDP per capita. This indicates that as people are earning more income, the homicide rate may not change because of this, perhaps due to the fact that homicide includes statistics like car accidents and suicides, which does not relate to GDP to a great extent.

TABLE 6. Regression of homicide rate on Gini coefficient and log GDP per capita

\begin{tabular}{lllll}
\hline \hline Source & SS & $\boldsymbol{d} \boldsymbol{f}$ & MS Number of obs & $\mathbf{8 3}$ \\
\hline \multirow{2}{*}{ Model } & $F(2,74)=$ & 20.51 & & \\
Residual & 4513.25365 & 22256.62682 & Prob $>F=$ & 0.0000 \\
& 8140.54635 & 74110.007383 & $R$-squared $=$ & 0.3567 \\
Total & Adj $R$-squared $=$ & 0.3393 & & \\
HomicideRate & 12653.8 & 76166.497368 & Root MSE $=$ & 10.488 \\
Gini & Coef. & Std. Err. $t$ & $p>t[95 \%$ Conf. & Interval] \\
LogGdpPerCapita & -8187809 & .15652125 .23 & 0.000 .5069057 & 1.130656 \\
_cons & -1.661763 & $1.347049-1.23$ & $0.221-4.345817$ & 1.022291 \\
\hline \hline
\end{tabular}

The regression of the homicide rate on the Gini coefficient and the log GDP per capita jointly is shown in Table 6 as well. The results differ considerably from the results on the theft rate. This indicates that the influence of Gini coefficient and log GDP per capita may vary among different categories of crime. The $R$-squared shows that the two factors could only explain $35.7 \%$ of changes in the homicide rate. As the Gini coefficient increases by 1 , the homicide rate tends to increase by approximately 0.818 . Possible explanations behind the unclear relationship between log GDP per capita and homicide rate is that there may be more motives for homicides then theft.

\section{CONCLUSION AND IMPLICATIONS}

In this paper I have analyzed the statistics for life expectancy, infant mortality rate, theft rate and homicide rates around the globe and their relation to the GDP per capita as well as the income inequality between countries. Inequality could be examined by means of the Gini coefficient: the lower the Gini coefficient, the more equal a country is likely to be. However, it is not only the level of inequality that plays a role but also the GDP per capita (or log GDP per capita). All variables that I examined are affected by at least one of the two indicators (Gini coefficient and log GDP per capita) to a certain extent. Life expectancy and infant mortality rate is affected by both the level of equality and the GDP per capita (the higher they are in a country, the higher the life expectancy and the lower the infant mortality). The 
impact of the GDP per capita is logarithmic. For theft rate, the Gini coefficient does not play a significant role but the GDP per capita is an important factor (somewhat counterintuitively, higher incomes lead to more theft). For homicide rate, the GDP per capita does not play a role, but the Gini coefficient is important (more homicides happen when the inequality is high). This proves that the impact of incomes and income inequality on the indicators of living standards might be complex.

There are some limitations to my research. It focuses on the aggregate data, which means that some statistics (e.g. within-country differences) could be ignored or missed out on. I could also examine additional factors such as the average income and the unemployment rate which could impact life expectancy, infant mortality rate and theft/homicide rates. As the living standards are increasing, people tend to enjoy a healthier lifestyle and therefore improve the quality of life variables. The level of public good provision could be another part that I could mention, since when the quality and quantity of the public goods increase, peoples' living standards including literacy rates are likely to increase as well; this would be related to the government's allocation of expenditure. Availability of guns could also be another substantial factor that affects homicide rate other than Gini coefficient and GDP per capita because more people having easier access to guns usually leads to a higher number of shootings. The unavailability of data could also be a factor that influence the final results, particularly for Gini coefficient, out of the 216 existing countries, I only gather the full set of data for 84 of them. Therefore, access to more data could further improve my results.

\section{REFERENCES}

Ayuningrat, M. P., Noermijati., \& Hadiwidjojo, D. (2016). Green product innovation's effect on firm performance of managerial environmental concern and green communication. Journal of Administrative and Business Studies, 2(2), 56-63. doi: https://doi.org/10.20474/jabs-2.2.1

Berkman, L. F., \& Glass, T. (2000). Social integration, social networks, social support, and health. Social epidemiology, 1(6), 137-173. doi:https://doi.org/10.1146/annurev-soc-070308-115926

Choe, J. (2008). Income inequality and crime in the United States. Economics Letters, 101(1), 31-33. doi:https://doi.org/ 10.1016/j.econlet.2008.03.025

De Maio, F. G. (2007). Income inequality measures. Journal of Epidemiology \& Community Health, 61(10), 849-852. doi: https://doi.org/10.1136/jech.2006.052969

de Meijer, C., O’Donnell, O., Koopmanschap, M., \& Van Doorslaer, E. (2013). Health expenditure growth: Looking beyond the average through decomposition of the full distribution. Journal of Health Economics, 32(1), 88-105. doi:https:// doi.org/10.1016/j.jhealeco.2012.10.009

Hairudinor, Hidayati, N., Muspiron., Tampubolon, E., \& Humaidi. (2017). The influence of transformational leadership and compensation on psychological well-being (study at Private Hospital Nurses in South Kalimantan Province). International Journal of Business and Economic Affairs, 2(5), 317-326. doi:https://doi.org/10.24088/ijbea-2017-25006

Kawachi, I., \& Berkman, L. F. (2003). Neighborhoods and health. Oxford, UK: Oxford University Press.

Kelly, M. (2000). Inequality and crime. Review of Economics and Statistics, 82(4), 530-539. doi:https://doi.org/10.1162/ 003465300559028

Liu, H., \& Dong, X. (2016). Influence of social relations on knowledge conflicts-an empirical study from Chinese universities. Journal of Administrative and Business Studies, 2(1), 8--18. doi:https://doi.org/10.20474/jabs-2.1.2

Putri, Y. R. (2015). Transformational leadership and its impact to lecturers intellectual capital factors in Telkom economics and business school Telkom University. International Journal of Business and Administrative Studies, 1(1), 35-41. doi: https://doi.org/10.20469/ijbas.10006

Qekwana, D. N., Oguttu, J. W., Venter, D., \& Odoi, A. (2016). Disparities in beef tapeworm identification rates in the abattoirs of Gauteng Province, South Africa: A descriptive epidemiologic study. Plos One, 11(3), 19-26. doi:https://doi.org/ 10.1371/journal.pone.0151725

Rafiah, K. K., \& Ariyanti. (2017). Role of transactional quality and relational quality to customer e-loyalty in marketplace C2C in Indonesia. International Journal of Business and Economic Affairs, 2(2), 116-126.

Stack, S. (1984). Income inequality and property crime: A cross-national analysis of relative deprivation theory. Criminology, 22(2), 229-256. doi:https://doi.org/10.1111/j.1745-9125.1984.tb00299.x 
United Nations. (2020). Transforming our world: The 2030 agenda for sustainable development. Retrieved from https: // bit.1y/3iYtyec

Wartika, K., Surendro, H., Satramihardja, I., \& Supriana. (2015). Business process improvement conceptual models to improve the efficiency of power consumption on computer use from the perspective of human resource performance. International Journal of Business and Administrative Studies, 1(3), 99-106. doi:https://doi.org/10.20469/ijbas.10004-3 